\title{
Varying Charges and Questionable Costs
}

\author{
Ari B. Hoffman, $M D^{7}$ and Andrew B. Bindman, $M D^{2,3}$ \\ 'Department of Medicine, UCSF Medical Center, University of California San Francisco, San Francisco, CA, USA; ${ }^{2}$ Departments of Medicine and \\ Epidemiology \& Biostatistics, San Francisco General Hospital, University of California San Francisco, San Francisco, CA, USA; ${ }^{3}$ Philip R. Lee Institute for \\ Health Policy Studies, University of California San Francisco, San Francisco, CA, USA.
}

J Gen Intern Med 30(11):1579-80

DOI: $10.1007 / \mathrm{s} 11606-015-3454-8$

(c) Society of General Internal Medicine 2015

$\mathrm{W}$ hen it comes to healthcare, all of us - patients, providers, payers, employers, and health systems - have more financial "skin in the game" than ever. Patients exposed to higher out-of-pocket costs now scrutinize their hospital bills as never before; insurance companies and employers use their leverage as major purchasers of healthcare to drive down costs; and health care managers seek new ways to efficiently deliver care to maximize value. In every case, getting costs under control requires an understanding of their basis.

Hospitals account for almost one-third of all healthcare expenditures, making them the largest slice of the healthcare pie. American hospitals cost nearly three times the OECD median per discharge when adjusted for costs of living. ${ }^{1}$ The challenge of understanding these costs is reflected in the hospital Charge Description Master, commonly referred to as the "charge master."

The charge master is a lengthy catalogue of non-discounted prices for services provided to patients, including lab tests, supplies used, and procedures performed. Hospital prices have increased almost three times the rate of general inflation since the 1980 s. $^{2}$ Only a small proportion of patients actually pay these prices, but those without the protection of insurance are at greater risk for being billed for the full charge, and disproportionately face bankruptcy as a result. ${ }^{3}$ Public and private insurers use their clout as high volume purchasers to negotiate lower rates of hospital reimbursement. In California, hospitals collect an average of $38 \%$ of their charge master prices billed to privately insured patients and $21 \%$ billed to Medicare. ${ }^{4}$

Hospitals use different formulas to determine charge master prices, with dramatic variability. In California, which mandated public charge master reporting in 2004, prices for the same service can vary up to 17 -fold across institutions. ${ }^{5}$ The article by Park et al. published in this issue of JGIM attempted to discover the factors that might explain this variation in charges across hospitals. ${ }^{6}$ The authors examined county measures of socioeconomic status, health status, health behavior, access to and quality of outpatient care, and the physical environment. They found that among 2871 hospitals nationwide, there was

Published online July 1, 2015 little statistical association between the 29 community measures they tested and hospital charges. The two exceptions were the percentage of uninsured in a county, which was associated with higher hospital charges, and the percentage of children living in poverty in a county, which was associated with lower hospital charges.

The association between rates of uninsured and higher charges is consistent with cost shifting - the idea that hospitals purposefully raise their charges to compensate for anticipated losses related to caring for the uninsured. Park et al. adjusted for differences in local wages, hospital market competition, hospital patient severity, as well as ownership type, and still found higher hospital charges in communities with more uninsured patients. Furthermore, the finding that hospital charges are lower in association with the percentage of children living in poverty is also consistent with the conclusion that hospitals raise their charges in an attempt to shift costs for the uninsured onto those who are insured. Since children living in poverty are categorically eligible for Medicaid, this demographic characteristic of a county would be expected to be inversely associated with the county's rate of uninsured.

The Affordable Care Act (ACA) was largely designed to reduce the number of uninsured, which should reduce the degree to which hospitals shift costs for the uninsured onto the insured. Congress anticipated this change as a source of potential savings to offset the cost of coverage expansion within the ACA by reducing the rate of growth for Medicare hospital payments over time.

Congress did not anticipate that its planned expansion of Medicaid within the ACA would become optional based on a subsequent Supreme Court ruling. ${ }^{7}$ Thus far, states that have expanded Medicaid coverage have experienced much greater reductions in the percentage of remaining uninsured as compared to states that have not. ${ }^{8}$ If the variation in the hospital charge master is indeed related to the rate of uninsured in a hospital's community, then we might observe a dramatically different growth rate in the hospital charges seen in Medicaid expansion and Medicaid non-expansion states.

A slower rate of growth of hospital charges in Medicaid expansion states might indicate that those with insurance coverage prior to the implementation of the ACA will experience financial benefits from the expansion of coverage to the uninsured. However, relying on the charge master to form judgments about the successes and failures of health care policies is indirect. In fact, the ratio of charges to costs has 
increased over time, perhaps due to the ability of private insurers to negotiate larger discounts as charges rise. ${ }^{9}$ Even today, we do not know how responsive the prices in the charge master are to changes in market conditions and what amounts are actually paid by various payers relative to those charges. Park et al. do their best to understand the underlying basis for the price variation within the charge master, but ultimately it is a very weak source of information.

To truly inform our understanding of health care costs and judgments about whether variation in provider prices is related to differences in community characteristics, we need a comprehensive database of the actual amounts paid for specific health care services. The ACA includes several cost control policies, but it does not include a requirement for payers to report their payments to health care providers.

At time of writing, 15 states have pursued price transparency through the establishment of a state mandated all payer claims database (APCD), and more than 20 others are considering similar legislation. ${ }^{10}$ APCDs have the potential to reveal whether health care policies and marketplace conditions are bending the cost curve and are thereby increasing health care value over time. Public dissemination of the payment information available from APCDs can also be used to activate patients as more cost conscious consumers in their choice of providers, particularly when they face financial consequences for some or all of their costs.

A comprehensive conceptual approach and sophisticated analytic tools, combined with timely and accurate data not only on charges, but on real medical expenditures, could lead to a breakthrough in the long struggle to slow the growth of health care costs and to increase the value of health care investments.

Conflict of Interest: The authors declare that they do not have a conflict of interest.

Corresponding Author: Ari B. Hoffman, MD; Department of Medicine, UCSF Medical CenterUniversity of California San Francisco, San Francisco, CA, USA (e-mail: ari.hoffman@ucsf.edu).

\section{REFERENCES}

1. Anderson C. Multinational comparisons of health systems data, 2014. The Commonwealth Fund, November 2014.

2. United States Department of Labor. 2015. Consumer Price Index. Bureau of Labor Statistics. Retrieved May 30, 2015 from http://data.bls.gov/cgibin/dsrv?cu.

3. Himmelstein D, Thorne D, Warren E, Woolhandler S. Medical bankruptcy in the United States, 2007: Results of a national study. Am J Med. 2009; 122(8):741-746.

4. Bai G. California's hospital fair pricing act reduced the prices actually paid by uninsured patients. Health Aff (Millwood). 2015;34(1):64-70.

5. Lagnado L. California Hospitals Open Books, Showing Huge Price Differences. Wall Street Journal, 27 December 2004. Accessed online June 9, 2015.

6. Park J, Kim E, Werner R. Inpatient hospital charge variability of U.S. hospitals. J Gen Intern Med. 2015. doi:10.1007/s11606-015-3352-0.

7. National Federation of Independent Businesses v. Sebelius, U.S. Supreme Court, p. 55-58, slip op., 132 S. Ct. 2566. 2012

8. Gunja M. Issue Brief: Health insurance coverage and the Affordable Care Act, Office of the Assistant Secretary for Planning and Evaluation, March, 2015.

9. Anderson G. From 'soak the rich' to 'soak the poor': recent trends in hospital pricing. Health Aff (Millwood). 2007;26(3):780-789.

10. Hodder L, Porter J, Love D, Peters A. Model All-Payer Claims Database Legislation. APCD Council and West Health Policy Center. May 2015. 